\title{
ACEPCIONES SEMÁNTICAS SUGERIDAS POR LAS DIFERENTES VERSIONES DE SINUHÉ
}

\author{
JOSÉ MANUEL GALÁN
}

CSIC. Madrid

La historia de Sinuhé es uno de los textos con el que los egiptólogos están más familiarizados. Se incluye dentro del corpus que los estudiantes han de manejar para su formación en el estadio de la lengua llamado egipcio clásico o medio ${ }^{\prime}$. Por otro lado, debido a su riqueza léxica y gramatical y debido a su contenido, ha sido objeto de numerosos estudios parciales en profundidad.

Sinuhé era un alto oficial de la corona al servicio de la reina. Cuando se encontraba con el príncipe heredero en el desierto líbico, el rey muere en su palacio en extrañas circunstancias. Por un texto literario contemporáneo ${ }^{2}$, un supuesto testamento político del rey fallecido, conocemos que éste fue víctima de una conspiración interna. Cuando Sinuhé se entera indirectamente de lo acaecido, teme por su vida, creyendo que lo relacionarían con los rebeldes, y huye. $\mathrm{Su}$ huida le conduce a tierras de Palestina, donde lo recoge una tribu nómada, acabando su éxodo en el Líbano, cerca de Biblos. Allí se convierte en jefe de una tribu y alcanza un gran prestigio en la región. A pesar del estatus y fortuna de que disfrutaba Sinuhé, su deseo era volver a Egipto, y así se lo transmitía a los egipcios que pasaban por su territorio y a los que acogía en su campamento. El nuevo rey egipcio es informado sobre la situación de Sinuhé y le invita a volver: le hace saber por carta que no hay cargos contra él

\footnotetext{
1 R. B. PArkinson, "Teaching, Discourses, and Tales from the Middle Kingdom", en S. Quirke (ed.), Middle Kingdom Studies, New Malden 1991, págs. 105-122, 113114.

${ }^{2}$ Enseñanzas del rey Amenemhat I a su hijo Sesostris I. Puede encontrarse la traducción de este texto y del de Sinuhé, en M. Lichtheim, Ancient Egyptian Literature, I, Berkeley - Los Ángeles - Londres 1973, págs. 135-139, 222-235; y W. K. SimpSON (ed.), The Literature of Ancient Egypt, New Haven - Londres 1972, págs. 57-74, 193197.
} 
y le promete que será tratado como un noble. Sin tardanza, Sinuhé regresa a Egipto, acabando sus días en la corte.

La historia de Sinuhé fue considerada un clásico incluso por los propios egipcios del II milenio a. C., utilizándose en las escuelas de escribas como modelo literario. Así, han llegado hasta nosotros treinta y cuatro versiones fragmentarias del texto ${ }^{3}$. Siete de las cuales están escritas sobre papiro y veintisiete sobre ostraca; todas ellas en letra cursiva o hierático, utilizando pincel y tinta negra. Algunos de los fragmentos incluyen correcciones posteriores en tinta roja.

De los siete papiros, seis son ligeramente posteriores al hipotético original, fechados al final del Reino Medio, en el siglo XIX a. C. La acción narrada discurre a mediados del siglo XX a. C., y su composición literaria supuestamente tuvo lugar poco después, es decir, a finales del siglo XX a. C. El resto de las versiones, un papiro y veintisiete ostraca, datan del Reino Nuevo, en su mayor parte del siglo XIII a. C.

El fragmento más antiguo es el Papiro Berlín 3022, conocido como la versión B. Su estado de conservación es bueno y es el que presenta un texto más completo, faltándole tan sólo el comienzo. Este papiro fue hallado en Tebas, en una tumba del Reino Medio contemporánea del texto, junto con copias parciales de El campesino elocuente y de El diálogo de un desesperado con su Ba, obras literarias también de esa época. La edición del texto hierático fue realizada por Alan Gardiner en $1909^{4}$, y el mismo autor publicó en 1916 una transcripción del hierático a signos jeroglíficos, un comentario filológico y una traducción del texto ${ }^{5}$. Por ser el más antiguo, el más extenso y estar bien conservado, la versión B del Papiro Berlín 3022 se ha convertido en el texto estándar, sobre el que se basan los

\footnotetext{
${ }^{3}$ R. КосH, Die Erzählung des Sinuhe, Bruselas 1990, pág. VI, donde se encontrarán las siglas correspondientes a cada versión. El autor transcribe a signos jeroglíficos los originales escritos en letra cursiva, disponiendo las versiones en paralelo para facilitar su comparación. Ver además la reseña de este libro por R. B. PARKINSON en Journal of Egyptian Archaeology 81 (1995) 225, quien añade la referencia a dos fragmentos de Sinuhé aún sin publicar.

${ }^{4}$ A. H. Gardiner, Die Erzählung des Sinuhe und die Hirtengeschichte, Leipzig 1909, láminas 5-15. Las láminas 1-4 son el facsímil de la versión R de Sinuhé, el papiro de Berlín 10499 (verso), que es el mejor texto para el comienzo de la narración.

${ }^{5}$ A. H. Gardiner, Notes on the Story of Sinuhe, París 1916.
} 
estudios particulares y las traducciones más aceptadas de la obra literaria.

Por otro lado, en el año 1952, John Barns editó la versión de Sinuhé contenida en un ostracon del Ashmolean Museum ${ }^{6}$, de Oxford; versión abreviada con las siglas AOS. El ostracon había sido adquirido en El Cairo en dos fragmentos separados que se cedieron al museo en 1940 y 1942, aunque el último no llegase a Inglaterra hasta 1945. Si bien los comentarios filológicos se redactaron con esmero, la edición en sí no es de gran calidad; entre otras peculiaridades, los comentarios están escritos a mano. El texto de Sinuhé del Ashmolean Ostracon es un ejercicio escolar del siglo XIII a. C., y por tanto muy posterior al Papiro Berlín 3022. El editor señala en sus conclusiones el valor de esta versión de Sinuhé como fuente para documentar y conocer el aprendizaje en las escuelas de escribas y la transmisión de un texto literario. Sin embargo, sus comentarios sobre los méritos lingüísticos del texto que edita son en numerosas ocasiones negativos. Barns concluye sobre AOS: «... su autor no sabía, y parece ser que ni a él ni a sus maestros les preocupaba, lo que significaban las palabras que escribía. La comparación desfavorable con versiones como B o R (ambas del Reino Medio) le conducen a uno a desestimar el testimonio de la versión del Ashmolean Ostracon incluso en los lugares donde los manuscritos anteriores y mejores son más oscuros» ?.

Por todas estas razones, por el hecho de ser un texto escolar, por ser 600 años posterior a las versiones más antiguas, por los comentarios desfavorables de su editor y por su pobre edición, el texto del Ashmolean Ostracon apenas se ha tenido en consideración en los estudios y traducciones de Sinuhé.

Inevitablemente, al ser producto de una tradición forjada a lo largo de varios siglos, la versión AOS contiene errores gramaticales y diversos tipos de corrupciones textuales: reinterpretaciones de un pasaje oscuro para hacer que tenga sentido, sustituciones de palabras o expresiones desconocidas por otras, interpolaciones, omisiones,

${ }^{6}$ J. W. B. BARns, The Ashmolean Ostracon of Sinuhe, Londres 1952. Mi agradecimiento a J. Malek, del Griffith Institute, por haberme facilitado un ejemplar de esta edición.

${ }^{7}$ Ibid., pág. 34. Quince años después, J. BARnS mantenía estas mismas opiniones en «Sinuhe's Message to the King: A Reply to a Recent Article», Journal of Egyptian Archaeology 53 (1967) 6-14, 13. 
etc. Se detectan en el escrito errores fonéticos, supuestamente producidos al dictarse el texto, y errores gráficos o visuales, producidos al copiarse mal de un modelo. Por otro lado, las interpolaciones ocurren con frecuencia cuando un texto es aprendido de memoria y luego fijado por escrito.

Sin embargo, el ostracon del Ashmolean Museum, de un tamaño excepcional, pues mide $88,5 \times 31,5 \mathrm{~cm}$., contiene gran parte de la obra literaria y, a pesar de ser un ejercicio escolar y una versión tardía, mantiene un correcto egipcio clásico y una notable similitud con las versiones de época más antigua, las cuales, hay que decir, también incluyen errores gramaticales y corrupciones del texto, producto de la transmisión de la que son fruto, al igual que AOS.

Si se analizan las diferencias entre las versiones B y AOS como representantes de dos épocas de la transmisión del texto, del Reino Medio (siglo XIX a. C.) y del Reino Nuevo (siglo XIII a. C.), se puede llegar a la conclusión de que AOS no es una mera recensión o degeneración de la versión anterior, sino que es fruto de una autoridad con cierta independiencia de criterio. En efecto, dejando a un lado los errores gramaticales de una y otra versión, bien sea por copiar u oir mal, las diferencias entre B y AOS tienen su lógica, una razón de ser, y son en su mayoría altamente significativas.

AOS añade, en diversos lugares de la narración, elementos nuevos al texto, que completan el mensaje o tratan de aclarar la idea que éste pretendía transmitir, expresándola con otras palabras. Aquí radica precisamente el valor de AOS, tanto para la mejor comprensión de Sinuhé, como para matizar el significado y uso de ciertas expresiones de la lengua egipcia ${ }^{8}$.

Veamos a continuación unos ejemplos de la información que puede extraerse de la versión de Sinuhé contenida en AOS cuando se compara con otras versiones del texto, ocho casos sobre aportaciones significativas de AOS para la mejor comprensión de términos y expresiones.

\footnotetext{
${ }^{8}$ Como ejemplos de crítica textual en egipcio antiguo, véase G. BURKARD, Textkritische Untersuchungen zu ägyptischen Weisheitslehren des alten und mittleren Reiches, Wiesbaden 1977; y D. Silverman, «Textual Criticism in the Coffin Texts», en W. K. SimpSON (ed.), Religion and Philosophy in Ancient Egypt, New Haven 1989, págs. 2953.
} 
1.<smiles>C1CC1[As]1CC1</smiles>

[Neferu] poseedora de veneración (R; Am; S; G; C; B3)

$$
2 \Delta]]_{\Delta}^{0} \leftrightarrow\left\{\begin{array}{l}
3 \\
0
\end{array}\right.
$$

[Neferu] quien ha partido hacia la veneración (AOS, 3)

La reina Neferu, hija del rey asesinado, Amenemhat I, y esposa de su sucesor, Sesostris I, es calificada al comienzo de la narración como "poseedora de veneración» (nbt im3h,) en seis versiones, mientras que AOS utiliza como epíteto la construcción egipcia de participio «quien ha partido hacia la veneración» (sbit $r$ im3h). Esta variante, a primera vista insignificante, aporta información sobre el término traducido por 'veneración' (im3h) ${ }^{9}$. Este sustantivo es comúnmente utilizado en las inscripciones para calificar a un difunto; la variante de AOS, «quien ha partido hacia la veneración», señala que la veneración no es una cualidad inherente al difunto, que éste adquiere de forma inmediata tras su muerte física o el enterramiento, sino que es un estado hacia el cual el difunto ha de caminar, una meta del individuo en su otra vida.

2. Alcancé las Murallas del gobernante, las cuales fueron construidas

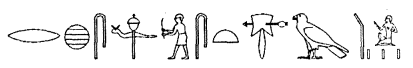

para detener a los styw $(\mathrm{B}, 17)$

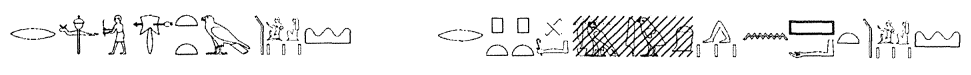

para detener a los styw, para aplastar a los que [atraviesan] la arena [es decir, a los que merodean por las dunas] (AOS, 15-16)

El último obstáculo que Sinuhé ha de superar en su huida hacia Palestina son las llamadas «Murallas del gobernante». La versión B señala que el propósito de la construcción de «las Murallas del gobernante», levantadas en el delta oriental del Nilo por monarcas

${ }^{9}$ Wörterbuch der Aegyptischen Sprache $(=W b$.) I 81, 18-23. 
egipcios ${ }^{10}$, era «detener a los styw». Este gentilicio es comúnmente traducido por 'asiáticos' o 'levantinos' ", términos que se refieren de forma genérica a los habitantes de Siria-Palestina. Cuatro versiones de Sinuhé, entre ellas AOS, indican además que las murallas o sistema de fortalezas en la frontera se construyeron «... para aplastar a los que atraviesan la arena» o «merodean por las dunas» (nmyw- ̌c ). El paralelismo que se establece en estas versiones entre los dos gentilicios parece indicar que el primero de ellos, styw, precisa de un equivalente semántico más definido que el de asiáticos o levantinos, un equivalente semántico relacionado directamente con la actividad apuntada por el segundo gentilicio, «merodear por las dunas», como es por ejemplo el apelativo nómadas ${ }^{12}$.

3. No sé lo que me llevó hasta esta tierra,

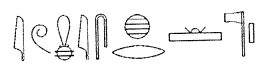

fue como un designio/plan de dios $(\mathrm{B}, 43)$

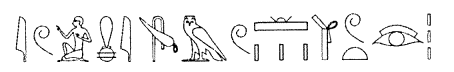

yo estaba como en un sueño (AOS, 25)

Sinuhé explica al jeque que le acoge durante su exilio en una región del Líbano las circunstancias de su huida y se excusa diciendo «no sé lo que me llevó hasta esta tierra». En la versión B continúa «... fue como un designio/plan de dios» (iw mi shr ntr r), mientras que en AOS dice «... yo estaba como en un sueño» (iw.i mi sšmw $r s w t)$. Ambas explicaciones para la acción emprendida por Sinuhé,

\footnotetext{
${ }^{10}$ S. QuiRKe, "Frontier or Border? The Northeast Delta in Middle Kingdom Texts", en The Archaeology, Geography and History of the Egyptian Delta in Pharaonic Times, Oxford 1989, págs. 261-274.

1 Wb. IV 328: «als Bez. der Beduinen Asiens»; R. O. FaulKner, A Concise Dictionary of Middle Egyptian, Oxford 1962, pág. 253: "Asiatics».

${ }_{12}$ El término styw tiene como opuesto en Sinuhé a los gobernantes y habitantes de los "países" (hk3 h3swt; h3styw). El territorio de los styw es denominado «tierras" $(t 3 w)$ y se contrapone a "países» ( $h 3 s w t)$, que hace referencia al área que abarca la autoridad reconocida de un gobernante asentado en un pueblo o ciudad. Sobre el contexto social del exilio de Sinuhé, cf. A. F. RaINEY, «The World of Sinuhe», Israel Oriental Studies 2 (1972) 369-408.
} 
si bien muy distintas, tienen el propósito común de liberar o eximir al protagonista de responsabilidad. La diferencia formal entre los dos mensajes muestra la estrecha relación que había en el antiguo Egipto entre el sueño y los designios de la divinidad ${ }^{13}$; relación atestiguada indirectamente en otros textos, como por ejemplo en la inscripción que relata el sueño del príncipe Tutmosis (IV) a los pies de la esfinge, durante el cual se le aparece el dios Hor-em-ajet, es decir, la esfinge, y le anuncia su pronta coronación, a condición de que el príncipe apartase la arena que comenzaba a cubrir sus patas ${ }^{14}$.

En AOS y en otras cuatro versiones Sinuhé añade un símil más para describir su desequilibrio psicológico al iniciar su huida: «(yo estaba como en un sueño) - dice Sinuhé-, como se ve un hombre del delta en Elefantina, un hombre de los cañaverales en Nubia» ( $m i$ gmh sw idhy $m$ lbw $s$ h $3 t m$ t3-sty). Este paralelismo es citado en la bibliografía egiptológica como fuente indirecta para documentar la diversidad cultural y lingüística en el antiguo Egipto, por otro lado bien atestiguada en copto muchos años después.

4.

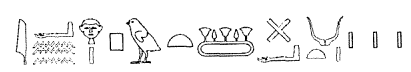

[Sesostris I] Él es osado, quien machaca los cuernos (B, 55; R)

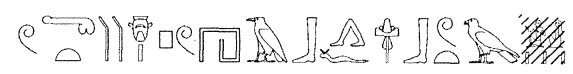

[Sesostris I] Él es valiente, derrota a las bandas (AOS, 29)

Tras exponer las circunstancias que le arrastraron hasta tierra extranjera, el jeque, llamado Amunenši, le pregunta a Sinuhé sobre la situación política en Egipto. Como respuesta, Sinuhé le dedica un panegírico al nuevo rey, Sesostris I, elogiando tanto sus méritos

13 P. Vernus, «Traum», Lexicon der Ägyptologie, VI, Wiesbaden 1986, págs. 745759; K. Zibelius-Chen, «Kategorien und Rolle des Traumes in Ägypten», Studien zur altägyptischen Kultur 15 (1988) 277-293. Véase también J. M. GALÁN, «Religious Beliefs in the Early History of Ancient Egypt», Aula Orientalis 12 (1994) 147-157, 150-151.

${ }^{14}$ W. Helck, Urkunden der 18. Dynastie, Helft 19, Berlín 1957, págs. 1539a-1544. 
políticos como militares ${ }^{15}$. Entre otras virtudes del monarca, Sinuhé destaca: «él es osado, quien machaca los cuernos $\left(i^{c}-h r p w t \breve{s} w p w t\right)$, en las versiones B y R. El paralelo de esta expresión en AOS dice: «él es valiente, derrota a las bandas» (wmt-ib pw h3b.f i3btyw). Esta variante permite interpretar que en un contexto militar el sentido de 'cuernos' es el de 'alas' o 'flancos' de un ejército. De hecho, este mismo símil es utilizado años después en los Anales de Tutmosis III, donde el ala sur y norte de su ejército en la batalla de Megiddo son denominadas, en lugar de con el término wpwt, utilizado por Sinuhé, con el término $d b$ que también significa 'cuerno' ${ }^{16}$.

5.

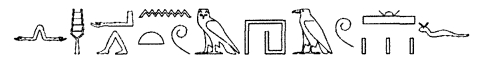

No hay quien esté de pie en sus alrededores (B, 55-56)

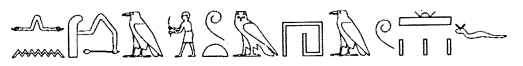

No hay quien luche en sus alrededores ([AOS, 30]; DM2)

Las versiones $\mathrm{B}$ y $\mathrm{R}$ dicen a continuación sobre el rey egipcio «... no hay quien esté de pie en sus alrededores». El sentido figurativo del verbo ' $h{ }^{c}$ 'estar de pie' en un contexto de relaciones, o mejor dicho, de conflictos internacionales, queda perfectamente aclarado en las versiones [AOS] y Deir el Medina 2, las cuales utilizan en su lugar el verbo ' $h 3$ que significa 'luchar': «... no hay quien luche en sus alrededores». El sentido de 'oponerse (a alguien)' que puede adoptar el verbo ponerse de pie ${ }^{17}$, deducido por contexto sobre todo en inscripciones reales, queda corroborado al comparar las distintas redacciones de este pasaje de Sinuhé. Koch, autor de la más reciente edición crítica de la narración literaria, publicada en 1990, se pregunta en una nota si esta variante de chc a chl3 es consciente o

\footnotetext{
${ }^{15}$ H. Goedicke, «The Encomium of Sesostris I», Studien zur altägyptischen Kultur 12 (1985) 5-28.

${ }^{16}$ K. Sethe, Urkunden der 18. Dynastie, IV, Berlín 1961, págs. 653, 11-12; 657, 1013.

${ }^{17} \mathrm{~Wb}$. I 218,5 .
} 
responde simplemente a un error de oído ${ }^{18}$. En vista de los casos que estamos presentando de variaciones lógicas del texto, la respuesta ha de ser la primera posibilidad. Las variantes de la versión AOS, muy posterior en el tiempo a las versiones $\mathrm{B}$ y $\mathrm{R}$, no responden la mayoría de las veces a un error de transmisión, sino que más bien son matizaciones o aclaraciones del significado.

6.

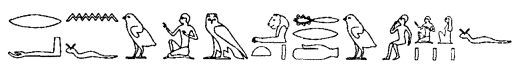

Me colocó al frente de sus hijos (B, 78)

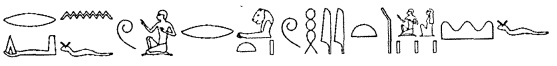

Me colocó al frente de su tribu (AOS, 36; DM2)

Sinuhé relata cómo el jeque Amunenši sentía gran estima por él. Mientras que la versión B menciona «me colocó al frente de sus hijos», la versión AOS y DM2 utilizan en lugar de la palabra $\underline{h} r d w$ 'hijos' el término whyt 'tribu': «me colocó al frente de su tribu». Como en los casos anteriores, esta variante permite comprender mejor el pasaje. El término $\underline{h} r d w$ no se refiere exclusivamente a hijos carnales, sino que se utiliza en Egipto en un sentido más amplio para referirse a una relación de dependencia o subordinación; por lo̊ que es más correcto traducirlo aquí no por 'hijo', sino por 'súbdito' ${ }^{19}$. El uso de términos de parentesco con un sentido extenso, y desde nuestra perspectiva con un sentido metafórico, no es un fenómeno exclusivo de Egipto, sino que está bien atestiguado en otras culturas del Próximo Oriente antiguo; como por ejemplo en la ciudad siria de Mari, cuyo archivo diplomático es contemporáneo a la época de Sinuhé y en el que los gobernantes de distintos países se refieren unos a otros con términos como hermano, padre o hijo según la posición jerárquica que cada uno ocupase con respecto al remitente ${ }^{20}$.

\footnotetext{
${ }^{18}$ R. КосH, Op. cit., pág. 34a.

${ }^{19}$ Nótese en este mismo contexto el paralelismo entre los términos tribu y país, en AOS, 38 y B, 86-87, respectivamente; cf. R. Koch, Op. cit., pág. 42.

${ }^{20}$ J. M. Munn-RAnKIN, "Diplomacy in Western Asia in the Early Second Millenium B. C.», Iraq 18 (1956) 68-110.
} 


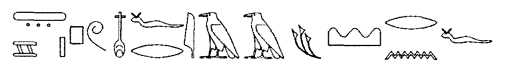

Su nombre era Iraru, era una buena tierra $(B, 81)$
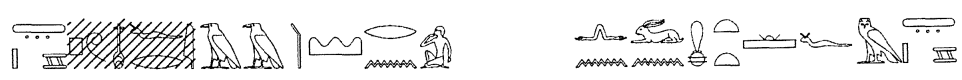

Su nombre era Iraru, era una buena tierra, no existe su igual [en la tierra] (AOS, 36-37)

Además de colocarle a la cabeza de sus hijos o de su tribu, Amunenši le ofrece la posibilidad a Sinuhé de que se asiente en el lugar que quiera de su frontera con las regiones circundantes. La tierra que Sinuhé elige entre los territorios fronterizos bajo la autoridad de Amunenši se llamaba Iraru ${ }^{21}$. Sinuhé afirma que «era una buena tierra» ( $t 3 p w n f r)$. Antes de comenzar a enumerar las riquezas naturales que allí se podían encontrar, la versión AOS añade una frase que aclara el sentido del adjetivo $n f r$ con el que Sinuhé califica la tierra de Iraru ${ }^{22}$; dice liceralmente a continuación «... no existe su igual en la tierra» ( $n n$ wn mitt.f $m$ t3). El paralelismo que se establece en la versión AOS entre la frase afirmativa «era una buena tierra» y la negativa «no existe su igual» revela que el adjetivo calificativo es en realidad un adjetivo superlativo: Iraru era una tierra buena por que no había otra igual, es decir, Iraru era la mejor tierra, se sobreentiende la mejor tierra en la frontera del territorio de Amunenši.

Las gramáticas de lengua egipcia, tanto de egipcio clásico como de neo-egipcio, no hacen mención alguna del adjetivo superlativo, considerando que éste no existe como tal en egipcio. Según las gramáticas, el superlativo se construye mediante perífrasis, compa-

${ }^{21}$ K. A. Kitchen, «Sinuhe's Foreign Friends, and Papyri (Coptic) Greenhill 1-4», en C. J. Eyre et al. (eds.), The Unbroken Reed. Studies in the Culture and Heritage of Ancient Egypt in Honour of A. F. Shore, Londres 1994, págs. 161-167, 161. Sobre el uso de escritura silábica en Egipcio Medio cf. J. E. Hoch, Semitic Words in Egyptian Texts of the New Kingdom and Third Intermediate Period, New Jersey 1994, págs. 488498.

${ }^{22}$ El adjetivo $n f r$ es también precisado en otro contexto. Tras escuchar las circunstancias que le arrastraron hasta tierras de Canaán Amunenši le dice a Sinuhé: «tú estás bien aquí (nfr tw '3) estando conmigo, [pues] tú oyes el habla de Egipto» (AOS, 21 ); cf. R. KocH, $O p$. cit., pág. 24 . Ver una tercera aclaración del uso del adjetivo $n f r$ en AOS, 36; R. КоcH, Op. cit., pág. 40. 
rando el sustantivo que se califica con su correspondiente abstracción. Por ejemplo, la perífrasis «ello es bueno comparado con cualquier cosa» quiere decir que «es lo mejor», o «ella es bella comparada con cualquier mujer» quiere decir que «es la más bella». Sin embargo, como ya sugirió Erik Hornung ${ }^{23}$, el adjetivo en egipcio es esencialmente superlativo. Un sustantivo es calificado con un rasgo en tanto que el emisor lo identifica como sobresaliente al resto de su clase en ese determinado rasgo y dentro de un mismo contexto. Así, por ejemplo y siguiendo a Hornung, nt $\underline{\text { r }}$ ' 3 , literalmente 'dios grande', significa en verdad 'dios grandísimo' o 'el dios más grande'. Como se ha apuntado antes, el paralelismo que se establece en la versión AOS entre la frase afirmativa "era una buena tierra" y la negativa «no existe su igual» es un buen ejemplo de cómo en realidad el adjetivo calificativo lo conciben los egipcios como un adjetivo superlativo.

8.

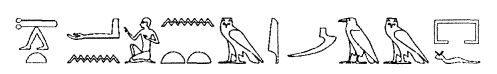

Tomé aquello que estaba en su tienda (B, 145; R)

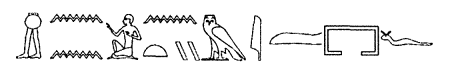

Me trajē aquello que estaba en su tienda (AOS, 56)

En la cúspide de su carrera como jefe tribal, Sinuhé es desafiado por un jefe de otra tribu. El duelo entre ambos marca el clímax narrativo de su exilio. Tras la victoria, atravesando el cuello de su anónimo rival con una de sus flechas, Sinuhé toma posesión de las pertenencias del vencido ${ }^{24}$. Esta última acción es expresada en la versión B y R mediante el verbo iti $i$, 'tomar', 'coger', mientras que la versión AOS emplea el verbo ini, 'traer'; dice Sinuhé: «Tomé aquello que estaba en su tienda» o "Traje aquello que estaba en su tienda».

\footnotetext{
${ }^{23}$ E. Hornung, Concepts of God in Ancient Egypt. The One and the Many, Ithaca 1982 (traducción de Der eine und die Vielen. Ägyptische Gottesvorstellung, Darmstadt 1971), pág. 181.

${ }^{24}$ H. GOEDICKE, «Sinuhe's Self-Realization (Sinuhe B 113-127)», Zeitschrift für ägyptische Sprache und Altertumskunde 117 (1990) 129-139.
} 
Esta variante no influye en la comprensión de la frase, pero el paralelismo que se establece entre los dos verbos sí arroja luz sobre el uso del verbo ini utilizado en AOS. Este verbo es generalmente traducido por 'traer' ${ }^{25}$, sin duda su significado básico, como bien indica el propio signo con el que se escribe, una vasija sobre dos piernas caminando. Sin embargo, en ciertas expresiones utilizadas en un contexto de relaciones o conflictos internacionales parece adquirir el matiz de 'traerse consigo' ${ }^{26}$; es decir, que adopta un sentido similar a 'tomar', 'adquirir', convirtiéndose así en sinónimo virtual del verbo iti $i$ utilizado en las versiones B y R. El uso del verbo ini y del verbo iți para el mismo pasaje de Sinuhé apoya la sinonimia entre ambos verbos, hasta ahora sólo deducida por contexto; como vimos antes en el ejemplo cinco para los verbos levantarse [en el territorio de alguien] y luchar [contra alguien].

Los ocho ejemplos que acabamos de analizar demuestran que la comparación y estudio crítico de las versiones de Sinuhé es una valiosa fuente de información sobre la lengua egipcia y especialmente sobre el significado y uso de ciertos términos ${ }^{27}$. Hasta ahora no había sido explotada esta posibilidad debido a la subestima de la que son objeto las versiones más modernas y escolares del texto, sobre todo la versión del Ashmolean Ostracon; subestima en absoluto justificada, como bien demuestran los pasajes citados.

Si bien la versión AOS fue redactada casi 600 años más tarde que la versión $B$, puede constatarse una notable semejanza entre ambas. Y a pesar de que AOS es un ejercicio escolar, la calidad gramatical y literaria se decanta entre una u otra versión según el pasaje concreto de que se trate. En los casos en los que una versión añade una o más palabras o incluso una frase que no se encuentra en su paralelo, éstas son siempre prescindibles, es decir, que su

\footnotetext{
${ }^{25} \mathrm{~Wb}$. I 90.

${ }^{26}$ Una expresión frecuente en los textos de carácter político para referirise a las victorias de la monarquía contra extranjeros rebeldes dice literalmente: «su majestad ha traido los límites de las tierras extranjeras" (ini $\underline{d} r w$ ), que no significa otra cosa que 'su majestad ha tomado las tierras extranjeras hasta sus límites', es decir, metafóricamente hablando, que 'se ha traido consigo los límites de las tierras extranjeras'; cf. $W b$. I 91, 1-3.

${ }^{27}$ Otros ejemplos de variaciones significativas de AOS con respecto a B pueden encontarse en, R. KoCH, Op. cit., págs. 24 y 40, 42, 51, 52, 66. Para la última variante señalada cf. J. M. GALÁN, Victory and Border. Terminology realted to Egyptian Imperialism in the XVIIIth Dynasty, Hildesheim 1995, pág. 28.
} 
función en el texto es la de aclarar o matizar la información de la oración principal a la que acompañan.

La versión AOS, como se habrá podido constatar, es más explícita en su expresión, característica que conduce a desvelar las claves semáticas y gramaticales de las versiones más antiguas.

La versión del Ashmolean Ostracon es un caso excepcional, pero a la vez instructivo, de cómo un texto en principio de escasa calidad, al ser un ejercicio escolar, y una versión mucho más tardía que otras conservadas, puede ser de gran valor lingüístico y literario.

Es además la versión AOS un ejemplo de transmisión peculiar de un texto, pues combina una notable similitud con otras redacciones a la vez que manifiesta cierta personalidad y criterio autónomo. Las reinterpretaciones o simplificaciones de ciertos pasajes señalan que su autor, supuestamente un escriba principiante, no redactó el texto simplemente de oido o de vista, sino que lo adaptó a sus conocimientos de la lengua clásica y a su gusto estético.

En este sentido, es difícil afirmar si hubo una versión original de Sinuhé de la que derivan las versiones más o menos desvirtuadas que han llegado hasta nosotros desde distintas épocas, o si por el contrario existieron desde el principio varias redacciones paralelas que recogían una tradición oral ${ }^{28}$. Lo que sí se puede afirmar hoy es que, a pesar de los casi 600 años que separan la redacción de Ashmolean Ostracon de la versión estándar de los papiros B y R, la versión AOS mantiene un lenguaje clásico de calidad y su autor alcanza la talla de los más antiguos redactores; por lo que esta versión, la del Ashmolean Ostracon, debe tenerse siempre en consideración a la hora de re-componer e interpretar el texto de Sinuhé.

${ }^{28}$ J. W. B. BARNs, Op. cit., pág. 35; ÍDEM, Journal of Egyptian Archaeology 53 (1967) 6-14, 13, sostiene que el autor de la versión AOS es parte de una tradición independiente de la estándar (B y R). Además, concluye que Sinuhé difiere sustancialmente del género de ficción, por lo que ha de considerarse como una verdadera autobiografía. 


\section{RESUMEN}

La comparación y estudio crítico de las versiones de Sinuhé es una valiosa fuente de información sobre la lengua egipcia, y especialmente sobre el significado y uso de ciertos términos. Hasta ahora no había sido explotada esta posibilidad debido a la subestima de la que son objeto las versiones más modernas y escolares del texto, sobre todo la versión del Ashmolean ostracon; subestima en absoluto justificada, como bien muestran los ocho pasajes analizados.

\section{SUMMARY}

The comparison and critical study of the different versions of Sinuhe is a valuable source of information on the Egyptian language, and particularly on the meaning and use of certain terms. This possibility has not been pursued so far because of the underestimation of later school versions of the text, specially the Ashmolean ostracon version. It is certainly an unjustified underrating, as the eight passages analysed in this paper show. 